\title{
A Comparative Study of Faculty Members' Career Advancement (Promotion) Systems in the United States and the Islamic Republic of Iran: Case Analysis of the University of Tehran and Portland State University
}

\author{
Mohammad Mehdi Tanaomi ${ }^{1} \&$ Robert Reza Asaadi ${ }^{2}$ \\ ${ }^{1}$ Faculty of Management, University of Tehran, Iran \\ 2 Department of Political Science, Department of International \& Global Studies, Portland State University, USA \\ Correspondence: Robert Reza Asaadi, Department of Political Science, Department of International \& Global \\ Studies, Portland State University, USA
}

Received: July 12, 2017

Accepted: July 31, 2017

Online Published: August 4, 2017

doi:10.5430/ijhe.v6n4p111

URL: https://doi.org/10.5430/ijhe.v6n4p111

\begin{abstract}
This article examines the similarities and differences in the systems for faculty career advancement in higher education institutions in the United States and the Islamic Republic of Iran. The analysis focuses on two specific cases: the University of Tehran and Portland State University. Through this paired comparison, we draw out the similarities between the two cases. Both cases are public universities and share similar criteria pertaining to productivity in research, teaching, and community outreach/service as central aspects in their respective faculty evaluation guidelines. On the other hand, we find significant differences in terms of the following parameters: the degree of centralization in the decision-making process regarding promotion and tenure, specific guidelines pertaining to the adherence to Islamic ideology in the Iranian case, which lack a comparative equivalent in the American case, the presence or absence of institutional mechanisms for faculty representation, and disparity in the ratio of tenure-track to non-tenure track faculty. The purpose of this article is to improve universities faculty members' career advancement (promotion) systems through the identification of effective practices in an effort to develop better organizational models of higher education.
\end{abstract}

Keywords: Comparative Analysis, Tenure; Faculty Promotion, University of Tehran, Portland State University, Islamic Republic of Iran, United States

\section{Introduction}

\subsection{Topic, Scope, and Objective}

How do institutions of higher education in different contexts (Note 1) reward faculty members through promotion and tenure? When studied comparatively, what are the salient aspects of similarity and difference that emerge between these career advancement systems? It is these questions, in the general sense, which frame the forthcoming analysis that is developed in this paper. More specifically, within the broader topic of faculty career advancement systems, the problem or scope condition that our paper addresses is the existing bias in favor of Western, and particularly American, models of career advancement systems in higher education. The objective of our study is to clearly describe how the systems for career advancement are organized and function in two illustrative cases in the United States and Iran, to explain the main points of similarity and difference between these systems, and to analyze which practices have been effective in each case in order to move toward a better model for faculty career advancement. Our paper addresses the existing bias in the literature on this topic in its nearly exclusive focus on how Western models of higher education can be disseminated to non-Western settings. Instead, our focus on effective practices, rather than the wholesale adoption of a particular organizational model out of its context of origin, introduces a pragmatic, collaborative perspective into this literature.

Our analysis is developed below in three sections. First, the article examines the guidelines for faculty career advancement at the University of Tehran. This section gives a brief historical overview of the University before moving on to an assessment of its institutional rules and procedures for faculty promotion and tenure. The key points emerging from this case analysis pertain to the similarities in emphasis regarding teaching, research, and community 
outreach/service between American and Iranian higher education systems, and also the differences concerning the emphasis of Islamic ethics in the Iranian university system. Furthermore, the Iranian system establishes clear quantitative parameters against which faculty are assigned scores; this form of evaluation lacks a clear equivalent in the American system. Next, the article transitions to its second substantive case study, Portland State University. Again, after providing a concise summary of the University, this section then focuses on career advancement rules and procedures, particularly noting the decentralization of this process from the University and college level to the level of individual academic departments. Also noted in this section is the role of representative bodies like the Faculty Senate and the American Association of University Professors (AAUP), as well as the growth of non-tenure track and part-time faculty under the broader trend of the corporatization of American higher education in recent years. Third, the article concludes by directly putting these cases in conversation with one another, focusing on the most relevant points of comparison and contrast between these two systems of higher education. The purpose of this comparative analysis is to identify best practices in each case, and suggest how a synthesis of these practices could lead to more effective and equitable guidelines for faculty promotion in the future.

\subsection{Literature Review}

The existing literature on faculty members' career advancement systems is multifaceted and addresses trends pertaining to, for example, the globalization and internationalization of higher education, the contraction of tenure and growth of non-tenure track faculty, and organizational analysis of the tenure review process itself. Altbach and Knight (2007) insightfully explore how globalization acts as a stimulus for the homogenization and commercialization of higher education programs and practices, and the authors observe that actors in the Global North control much of this process. Related to this observation, Youn and Price (2009) offer a critical analysis of the rules governing faculty promotion and tenure in the United States from the 1970s to 1990s. Youn and Price (2009) highlight how the organizational rules associated with faculty promotion and tenure are representational of the shared values of the university itself, and therefore function as a way to symbolize and convey the legitimacy of the environment. The insight here is that organization rules are nested within a more implicit cultural context, and are therefore always value-laden and constructed in and through routines which reinforce the organizational identity of the institution. Other works in this literature offer a less theoretically-driven analysis, and opt instead for a more policy-based approach. One example of this policy-focused trend in the literature comes from Gross-Schaefer, Gala, Jaccard, and Vetter (2015), who argue for the need for tenure system reform in the United States. These authors helpfully survey the debate on the current state of the tenure system and explore several options for its future reform, including: maintaining the status quo, full abolishment, the abolishment of indefinite tenure, and the creation of regional, supra-institutional tenure status. Through this analysis a clear picture emerges which focuses the debate surrounding the degree to which the faculty career advancement decisions are subject to oversight by entities advocating on behalf of faculty, and the negative consequences of the contraction of tenure in terms of declining academic freedom and the growth of underemployed adjunct faculty. Ott and Cisneros (2015), also explore the precarious position of non-tenure track faculty in American higher education. The relationship between tenure-track and non-tenure track faculty experiences and the consequences of the contraction of tenure is a recurrent theme in this literature. In a similarly critical vein, Bradley et al. (2017), reflect a common theme in the literature on faculty members' career advancement systems: the question of equity. These authors focus on music faculties in Canadian higher education, and their findings suggest that explicit rules and greater transparency in the tenure process were helpful in reducing ambiguity and perceptions of inequity, particularly among women and persons of color. The authors explain how university administrators advocated for greater flexibility in the tenure review process, but how this flexibility created the perception of a 'moving bar' for evaluation and the lack of clear, objective criteria in terms of teaching and research benchmarks for career advancement.

\section{University of Tehran}

Located in central Tehran, the University of Tehran is the symbol of higher education in Iran. Rooted in Jondi Shapur University, which dates back over 2,000 years, the idea of the University of Tehran in its traditional form was established seven centuries ago. It was founded firstly in religious seminaries, (Note 2) and in the modern era the University evolved from a religious structure to a more modern and academic structure of higher education. As such, the modern University of Tehran was inaugurated in the winter of 1934.

The contemporary University of Tehran is a public university with a student population of approximately 55,000 including online and remote students, and over 2,100 faculty members. The University publishes more than 50 scientific journals, many of which are listed with International Scientific Indexing (ISI). 
Career advancement of faculty members of all the universities in Iran is subject to specific quantitative parameters that reflect the priorities of the society. Faculty members are evaluated using a point system with specific categories and sub-categories as established by the Supreme Cultural Council, whose decisions can only be overruled by Iran's Supreme Leader. This system emerged during Iran's Cultural Revolution (1980-1983), which was the initial period following the Iranian Islamic Revolution. During this time, the academia of Iran was purged of non-Islamic influences (including even traditionalist, non-political doctrines) in order to bring academic institutions in line with the doctrine of revolutionary political Islam. The chairman of the Supreme Cultural Council is the President of Iran, Hassan Rouhani. This 41-member body sets the guidelines for faculty evaluation and promotion, which are then implemented through government ministries. More specifically, state-run universities in Iran are under the supervision of Iran's Ministry of Science, Research and Technology (for non-medical universities) and the Ministry of Health and Medical Education (for medical universities) (Islamic Republic of Iran Ministry of Science, Research, and Technology, 2017).

The Office of the President of the University of Tehran includes the following institutional entities: Board of Trustees (BOT), President of the University, and University Council. Members of the Board of Trustees include the Minister of Science, Research and Technology, the University President, four to six scientific, cultural, or social personalities who have an effective role in the development and expansion of the University, and a representative of the Management and Planning Organization. In order to elect the University President, the Minister of Science, Research and Technology selects some of the academic personalities through consultation and then proposes them to the Supreme Cultural Council. The candidate is then appointed as University President after being confirmed by the Council by the decree of the Minister. Lastly, the University Council is one of the most important entities of decision-making regarding the general policy of the University. The University Council is comprised of the Board of the Presidency, Deans of the University's colleges and research institutes, and other affiliated research and educational centers and complexes (University of Tehran, 2017).

\subsection{Career Advancement Decisions Criteria}

Having briefly outlined the history and institutional structures of the University, it is now helpful to consider the specific criteria for faculty evaluation at the University of Tehran. In the current guidelines outlined by the Supreme Cultural Council, there are four criteria for faculty evaluation and promotion: teaching, research, service/scientific-executive activities, and cultural activities. As will be shown in the following section on Portland State University, the categories of teaching, research, and community outreach/service are common in both the United States and Iran. Also, like Portland State, the implementation of faculty evaluation at the University of Tehran is significantly devolved from the University level to the departmental level. In effect, this means that department chairs and college deans are more involved in the actual process of faculty evaluation than the larger administrative units, such as the office of the president and overarching university administration, which establish these guidelines.

At the University of Tehran, the Audit Board, with its Expert Commission and in collaboration with a committee of each academic unit, is the sole authority which makes decisions on rank promotion. Furthermore, this entity also is tasked with identifying the scientific decline of faculty members. The Audit Board applies a point-system with specific minimum and maximum values across the four criteria for faculty evaluation mentioned above. Each of these criteria includes several items with different minimum and maximum values. Concerning the assessment of faculty members based on cultural activities, the University reviews the extent to which all activities of the faculty member conform to the combination of science and Islamic ethics, based upon the enforcement and promotion of theism consistent with the Constitution of the Islamic Republic of Iran and Islamic values. In order to facilitate this specific cultural evaluation, a special cultural commission is used to evaluate the faculty member. This body includes a representative from the office of the Supreme Leader, a cultural deputy of university students, a faculty representative, as well as representatives from the University faculty and administration of the specific department or institute in question. The minimum requirements for faculty members' rank promotion are summarized in Table 1.

Table 1. Faculty Members' Rank Promotion System

\begin{tabular}{lll}
\hline Rank Promotion & Minimum Points & Tenure in Current Rank \\
\hline From Assistant to Associate Professor & 110 & 4 years \\
\hline From Associate to Full Professor & 120 & 3 years \\
\hline
\end{tabular}


The faculty members' rank promotion process at the University of Tehran is similar to Portland State University's as it is discussed later in this article. The faculty members at the University of Tehran are generally full-time or tenure employees. The growth in non-tenure track faculty in recent years associated with the corporatization of higher education witnessed in the United States has not been mirrored in the Iranian system of higher education.

Table 2. Countable Points from Cultural, Training, Social Activities of Faculty Members of Institution

\begin{tabular}{lll}
\hline Subject & $\begin{array}{l}\text { Minimum } \\
\text { Points }\end{array}$ & $\begin{array}{l}\text { Accepted } \\
\text { Maximum } \\
\text { Accepted Points }\end{array}$ \\
\hline $\begin{array}{l}\text { Books, articles, and publications of new and } 10 \\
\text { distinguished piece of art with Islamic } \\
\text { approach in cultural, training, and social } \\
\text { areas... }\end{array}$ & & \\
\end{tabular}

The assessment of faculty members' activities in teaching focuses on their ability to train students and effectively communicate information in their field of study.

Table 3. Countable Points from Teaching Activities of Faculty Members of Institution

\begin{tabular}{lll}
\hline Subject & Minimum Accepted Points & Maximum Accepted Points \\
\hline Teaching quality and quantity & 20 & 40
\end{tabular}

The evaluation of faculty members' research activities is also central to the evaluation process. Emphasized in this category is the ability of faculty to discover and develop facts through their scientific research, to help meet society's needs, and to develop the boundaries of knowledge and expand the frontiers of technology.

Table 4. Countable Points from Research, Technology Activities of Faculty Members of Institution

\begin{tabular}{lll}
\hline Subject & Minimum Accepted Points & Maximum Accepted Points \\
\hline Publications & Based upon scientific rank & No ceiling
\end{tabular}

Notably, the maximum point allocation for research activities has no ceiling, meaning that, at least in theory, this category could prove to be the most impactful in decisions regarding promotion and tenure. Lastly, the service, scientific, and executive activities category emphasizes faculty members' contributions to science, knowledge, research, and technology which may fall outside of the more narrow rubrics of teaching and research, including, for instance, executive management or contributions to other projects relevant to community development.

Table 5. Countable Points from Scientific. Executive Activities of Faculty Members of Institution

\begin{tabular}{lll}
\hline Subject & Minimum Accepted Points & Maximum Accepted Points \\
\hline Community outreach/service & 10 & 35 \\
\hline
\end{tabular}

In summary, the Supreme Cultural Council established all university guidelines and regulations in Iran's system of higher education. As a consequence of this organizational characteristic, the faculty promotion system is centralized around this entity. As mentioned, the oversight of faculty members' contributions to cultural activities has its own centralized entity in the form of the Expert Commission of the Audit Board.

\subsection{Career Advancement System Limitations}

It is not an easy nor straight-forward task to evaluate faculty member practices concerning the promotion of Islamic values. The sub-criteria which describe Islamic practices and assign specific point values to them (Note 2), such as 'continuing in belief / persuasion,' and 'fidelity to the religious values, culture, national interest, revolution,' and 'honesty, safekeeping, trusteeship, custody,' are very difficult if not impossible for the Expert Commission to effectively and accurately assess. Furthermore, there is a lack of effective organization in higher education in Iran. Faculty governance, from departments to colleges, and to the University, and the notion of shared participation in this governance, is not a tradition or shared norm at the University of Tehran. It is certain that such participatory faculty governance, in the form of faculty participation in university committees, commissions, audit boards, and other institutional structures, would make a significant contribution to the effective governance of the University.

According to the Fifth and Sixth Planning Statements of the Islamic Republic of Iran, the University of Tehran should aim to employ the best university educators in full-time faculty positions; however, retaining these qualified individuals has been a challenge. One way to create a more sustainable environment for faculty members is to trust them and empower them through institutions of faculty governance. This does not mean the uncritical imitation of 
Western practices, or the denial of the shortcomings of these institutions, such as the corporatization of American higher education, or the disempowerment of Adjunct and non-tenure track Faculty. Instead, the point is to examine how best practices can be synthesized and adopted across systems of higher education, and one such improvement is the establishment of institutional mechanisms through which faculty members can participate in the establishment and implementation of the processes by which they will be evaluated for career advancement.

The University of Tehran's Third Strategic Planning Statement (2017-2012) calls for the sustainable development of the University, and emphasizes three primary goals and strategies to achieve these goals. The first goal is to improve the international status of the University of Tehran by expanding and promoting international educational cooperation. Second, the Strategic Planning Statement emphasizes the importance of promoting research and the practical, commercial effects of research through building up innovative and entrepreneur human capital. Thirdly, the University aims to improve the ethical and social responsibility of faculty, staff, and students by enforcing professional ethics and promoting the well-being of the University community. These three aims invite greater collaboration between the University of Tehran and institutions of higher education within Iran, in the Middle East region, and internationally. The desire to build an atmosphere which sustains scientific innovation alongside Islamic principles does not foreclose cooperation with international partner institutions. In fact, this type of collaboration is precisely the subject of the Strategic Planning Statement's first goal: improving the international status of the University.

\section{Portland State University}

Portland State is a public research university with a student population of nearly 30,000 and approximately 1,600 faculty members (Portland State University, 2017). Originally founded in 1946 and located in Vanport, Oregon, the institution relocated to its current location in Portland, Oregon in 1952 (Portland State University, 2017). As a public institution, the procedures for faculty evaluation and promotion must be consistent with the rules outlined by the Oregon State System of Higher Education (Oregon Administrative Rules of the Oregon State System of Higher Education, 1996). Governing control of Portland State University is vested in a Board of Trustees (BOT), which assumed this control from the Oregon State Board of Higher Education (SBHE). The institutional legacy in terms of the continuity in the administrative rules and policies associated with promotion and tenure from the State Board of Higher Education to the Board of Trustees is substantial, and one can observe the similarities between Portland State and other public universities in the state of Oregon in this regard (Oregon State University's Faculty Handbook, 2016). The Board of Trustees is comprised of 15 members who are appointed to this position by the Governor of the state of Oregon. While the Board of Trustees itself is required to convene only a minimum of four times per year, much of their activities are carried out at the committee level, and the Board's committees meet with greater regularity. The Board is required to include one faculty member, one staff member, and one student of the University, all of whom serve two-year terms, and the remaining 13 board members serve four-year terms (Bylaws of the Board of Trustees of Portland State University, 2016).

Furthermore, Portland State maintains that faculty evaluation and promotion rules and procedures must remain consistent with the agreement between the University and the Portland State Chapter of the American Association of University Professors (AAUP), and that these guidelines are not subject to change or suspension unless prior approval is given by the Faculty Senate. Academic faculty at Portland State University exercise their power to promote faculty welfare through the institutional mechanism of the Faculty Senate, which according to the preamble of the Constitution of the Portland State University Faculty has the broad mandate, "To ensure the orderly development of our educational programs and policies; to facilitate communications and cooperation among our officers of administration and ourselves as a university faculty; and to promote the stable growth and continued improvement of higher education in the State of Oregon..." (Constitution of the Portland State University Faculty, 2016). The current Faculty Senate is composed of 64 members from across the University's different colleges, and is guided by a Steering Committee.

\subsection{Career Advancement Decisions Criteria}

The University's current guidelines for faculty evaluation and promotion were adopted by the Faculty Senate on June 12, 1996, and have most recently been revised and reapproved on July 1, 2014 (Portland State University, 2014). In an effort to establish equitable assessment, and in recognition of the uniqueness of individual departments and academic disciplines across the University, the implementation of faculty evaluation is significantly devolved from the University level to the departmental level. Effectively, this means that chairs of department and deans at the college level are more involved in the actual process of faculty evaluation than larger administrative units, such as the office of the University president and overarching university administration. The result of this devolution is that 
departmental guidelines for faculty evaluation and promotion often vary in terms of the interpretation of the often general criteria, striking a compromise between the more specific disciplinary requirements and the broader academic mission of the University.

The three key parameters for faculty evaluation at Portland State, like most public research universities in the United States, are as follows: research, teaching, and community outreach/service. The University's guidelines for tenure, promotion, and merit increases explains this three-pronged approach in the following: "Scholarly accomplishments, suggesting continuing growth and high potential, can be demonstrated through activities of: research (including research and other creative activities), teaching (including delivery of instruction, mentoring, and curricular activities), and community outreach" (Portland State University, 2014).

In accordance with its mission as a research institution, the singular most important aspect of promotion at Portland State is scholarly production, and as such we might think of this as the proverbial 'coin of the realm' in career advancement. The University emphasizes the importance of the principle of academic freedom in this regard, noting that it is the individual responsibility of each faculty member to define his or her own scholarly agenda, and that the scope of research topics is therefore not delimited by the University itself. In defining what constitutes 'scholarship' per se, the University guidelines emphasize the expressions of discovery, integration, interpretation, and application. The practices encapsulated under these expressions of scholarship include building cumulative knowledge, making connections between theory and practice, problem-based and policy-relevant research, and theory generation and refinement. The criteria for determining what constitutes high-quality, significant scholarly production is assessed through the application of the following six somewhat broad assessment benchmarks: clarity and relevance of goals, mastery of existing knowledge, appropriate use of methodology and resources, effectiveness of communication, significance of results, and consistently ethical behavior (Portland State University, 2014, p.5-7). Again, because the actual implementation of faculty evaluation is devolved largely to the departmental level, how these categories are interpreted and applied on a case-by-case basis varies across departments and even within a single department over time. That fact notwithstanding, the most significant factor in terms of academic research in determining career advancement is published contribution to knowledge in one's field of study. This most typically comes in the forms of the publication of books and articles in peer-reviewed academic journals, successful grand proposals, and presentations at academic conferences. Furthermore, not only the quantity of publication, but the quality of publication is often a key consideration, with the Portland State guidelines noting: “... evaluation should consider whether publications are refereed (an important form of peer review) as an important factor. In some fields, evidence of citation or use of the faculty member's research or creative contributions by other scholars is appropriate" (Portland State University, 2014, p. 8-9). The exact nature of publication will of course vary across different colleges and departments, but the emphasis on published material in well-respected and oft-cited publications in one's field of study seems to be a universal metric of evaluation.

Along with research, the second significant factor in the career advancement process at Portland State is an assessment of a faculty member's effectiveness in teaching. Alongside the measure of scholarly production, accomplishments in teaching and mentoring are used to determine the merit for promotion. Effective teaching implies proficiency as a lecturer and discussion leader, the ability to create clear learning expectations through syllabi design, provide timely and helpful feedback on student work, and demonstrate expertise in one's field of study. As the Portland State faculty promotion guidelines summarize: "Evaluation of performance in this area thus should consider creative and effective use of innovative teaching methods, curricular innovations, and software development" (Portland State University, 2014, p. 10). As such, Portland State encourages faculty to practice a form of continual on the job training in the domain of pedagogy, and also encourages faculty to publish in pedagogical journals, thus reflecting the nexus of the research and teaching aspects of faculty evaluation. In reviewing faculty for tenure or promotion, some of the items which are used to demonstrate teaching proficiency include: syllabi and other course material, examples of special assignments and projects that reflect pedagogical innovation, formal student evaluations, peer review, the results of student supervision, publication in the field of pedagogy, grant proposals for curricular development, awards and honors for teaching, and professional development specific to building one's expertise as a teacher (Portland State University, 2014, p. 11).

Lastly, the third consideration in career advancement at Portland Stand is the somewhat broad, residual category of service and community outreach. Like research and teaching, this is described as a 'significant' factor in determining faculty career advancement, though again as a consequence of the decentralization of decision-making, exactly how significant this factor is compared to accomplishments in research and teaching is unclear. Activities falling under the category of community outreach are associated with what might be considered as a faculty member's role as a public intellectual. This includes activities that draw on one's scholarly expertise, and might include, for example, 
planning events in the community (literary or artistic festivals, public debates, lectures, etc.) or contributing to public discourse by helping define, conceptualize, or formulate policy regarding a particular social issue. Departments are advised to evaluate a faculty member's community outreach "creatively and thoughtfully" (Portland State University, 2014 , p. 12). The ambiguity of this metric speaks to the difficulty of assessing what is meant by meaningful community outreach. As with research and teaching, what this means in practice is that community outreach is measured largely by quantifiable standards of evaluation pertaining to publication, receipt of awards and honors, clear contribution to public policy, or, perhaps the most flexible measure, statements of evaluation from clients and peers attesting to the efficacy of community outreach of the faculty member. Lastly, in terms of service (or what is sometimes referred to as governance), faculty members bids for promotion are evaluated by considering the extent of one's participation in committees in one's department, college, and/or university, participation in the University committee through advising and attending significant events (such as commencement), and other professional service, such as serving as a reviewer or editor for an academic journal, or organizing a professional meeting in one's field of study. In sum, research, teaching, and professional service/community outreach are the three criteria which determine career advancement at Portland State, and in this regard Portland State is reflective of the broader system of American public institutions of higher education.

\subsection{Faculty Status: Corporatization and the Trend toward Non-Tenure Track Faculty}

One of the most significant aspects of the status of faculty at Portland State, and indeed in the American system of higher education writ large, is the increasing tension between tenure-track and non-tenure track (adjunct) faculty. At Portland State, for instance, non-tenure track faculty (that is, appointments at less than .5 FTE) are not covered by the faculty evaluation and promotion guidelines outlined above. Non-tenure track (adjunct) faculty are the largest proportion of faculty at Portland State University, making up 47\% of total faculty. The faculty ranking system at Portland State is premised on the egalitarian notion that “... a vital University depends on the active participation of all of its members" (Portland State University, 2014, p. 13). In the remarks below some of the ways in which this principle has failed to become manifest in practice will be highlighted. In theory, then, the faculty ranks at Portland State establish the following tenure-track positions: Assistant Professor, Associate Professor, Professor, and Emeritus. Concerning career advancement, attaining the rank of Assistant Professor is generally contingent on achieving the highest degree in one's field of study, which for most fields is a doctorate. In rare exceptions, given outstanding achievement, a candidate may be placed at the rank of Assistant Professor without meeting this terminal degree requirement, though the Portland State guidelines note that this is rare.

The first step in the tenure-track promotion process involves the advancement from the rank of Assistant Professor to Associate Professor. The Portland State guidelines specify the circumstances for this advancement in the following: "Promotion to the rank of Associate Professor requires the individual to have made contributions to knowledge as a result of the person's scholarship, whether demonstrated through the scholarship of research, teaching, or community outreach" (Portland State University, 2014, p. 14). Again, one observes the repetition of the three key parameters for career advancement outlined in the previous section: research, teaching, and community outreach/service. Furthermore, a faculty member is not eligible for promotion to the rank of Associate Professor until their third year as an Assistant Professor, and length of time in rank is not considered alone to be a sufficient reason for promotion. As the Portland State guidelines note: "In the usual course of events, promotion to Associate Professor and granting of indefinite tenure should be considered concurrently, in the sixth year in rank as an Assistant Professor" (Portland State University, 2014, p. 14). The timeline, then, for promotion from the rank of Assistant Professor to the rank of Associate Professor is three to six years. If the bid for promotion is successful, then the candidate is granted indefinite tenure. After at least four years as an Associate Professor, excepting what the Portland State guidelines terms 'extraordinary cases,' a faculty member becomes eligible for advancement to the rank of Professor, and again length of time in the rank of Associate Professor is not used as sufficient justification for promotion. Instead, the main criteria for promotion is significant contribution to one's field of study in the tripartite domains of research, teaching, and service/community outreach. The evaluative criteria for these accomplishments are more rigorous in the progression from Associate Professor to Professor than they are described in the promotion from Assistant Professor to Associate Professor, with the added modifiers of 'distinguished accomplishments' to one's field of study, and 'leadership or significant contributions' to professional activities added to the earlier, lower benchmarks of 'contributions' to one's field of study, and performing one's 'fair share' of professional service activities (Portland State University, 2014, p. 14).

The above description of the promotion from Assistant Professor - Associate Professor - Professor gives a broad sketch of the tenure-track career advancement process at Portland State, but what about the career advancement prospects for non-tenure track faculty? The remainder of this section will examine the largely parallel career 
advancement system for non-tenure track faculty at Portland State, as indeed this is an instructive case of the broader trend in American higher education toward the part-time, contingent, and non-tenure track model that is symptomatic of what some scholars of higher education have terms the corporatization of the American public university (Mills, 2012).

The main distinction among non-tenure track faculty in the Portland State system is between full-time and part-time (adjunct) faculty. Full-time, non-tenure track faculty are ranked most commonly as either Instructors or Senior Instructors (with two gradations, Senior Instructor I and Senior Instructor II, based largely on departmental discretion and extraordinary achievement). Fixed term appointments of all types are not eligible for tenure, and therefore there is not a clear career path in moving from a non-tenure track to a tenure-track position. The only formal reference to such a transition is the passing remark that "A non-tenure track appointment does not foreclose the possibility that a department may wish to consider that faculty member for a tenure-related appointment" (Portland State University, 2014, p. 21). Disentangling the meaning of that statement is not an easy task, and the opacity of the remark is reinforced by a following sentence which describes a 'mutually acceptable written agreement' which should be arrived at by the faculty member and the institutional representative of the University to effect such a transition. Simply, the process by which one would make such a transition is not clearly described in the Portland State guidelines. Additionally, as these guidelines make explicit, non-tenure track positions lack job security, as demonstrated in the following point on the definition, use, and conditions of faculty appointments: "It should be understood that non-tenure track fixed term appointments are for specified times and no reason for a decision not to reappoint need be given" (Portland State University, 2014, p. 20).

\subsection{Career Advancement System Limitations}

According to a March 2017 report by the American Association of University Professors, contingent (non-tenured) faculty now constitute 70.4\% of all faculty jobs in American universities (A Climate of Fear for Adjunct Faculty, 2017). The tendency toward contraction of tenure in recent decades in American higher education is problematic because, as the AAUP puts it, it lays bare a range of issues, including “... a lack of due process that protects academic freedom, exploitative pay and working conditions, and, frequently, no provisions for participation in the governance of institutions of higher education" (A Climate of Fear for Adjunct Faculty, 2017). In fact, nationally in the United States, full-time tenured and tenure-track faculty constitute less than $30 \%$ of all academic faculty, and faculty with part-time appointments now comprise the largest portion of the academic work force at $40 \%$ (A Climate of Fear for Adjunct Faculty, 2017). At Portland State, the shift from full-time to part-time workers is clear by examining the number of student credit hours taught by these different groups of faculty. In the fall 2016 term, tenured/tenure-track (full-time) faculty at Portland State taught a total of 91,392 student credit hours (36\%), while fixed-term (full-time, non-tenure track) faculty taught 73,992 student credit hours (29\%), and, adjunct (part-time, non-tenure track) faculty taught 89,196 student credit hours (35\%).

These trends in the growth of part-time, contingent, and adjunct faculty and the contraction of tenure relate to the broader question of what systems are in place at the University level for the career advancement and promotion of faculty. As these decisions are guided by the University administration through the Board of Trustees, it is worth considering how non-faculty, administrative workers have seen their own career advancement prospects change in recent years. According to the AAUP, "Administrative pay continues to rise faster than faculty pay. In 2016-17, the average salary for presidents was $\$ 334,617$, an increase of 4.3 percent over 2015-2016. Presidents now earn nearly four times as much as full professors at private doctoral institutions and more than three-and-a-half times as much as those at public doctoral institutions" (Flaherty, 2017).

In short, although faculty have experienced the contraction of tenure and the growth of part-time, adjunct employment, university administrators have not only not experienced such belt-tightening, but in fact have seen their compensation continue to grow. This exemplifies what some scholars of higher education refer to as the 'corporatization' of American higher education. In the case of Portland State, like many American universities, this includes not only the contraction of tenure and expansion of administrative pay, but also the rising costs of tuition. For example, the Board of Trustees at Portland State unanimously voted to raise in-state tuition by $9 \%$ in the 2017-2018 academic year from the 2016-2017 figure (which itself had increased by 4\% from the year prior) (Flaherty, 2017). Furthermore, adjunct faculty have no representation in the Faculty Senate at Portland State, which is the main representative body that must approve changes to the policies and procedures related to career advancement and promotion. Thus, in effect, nearly half of faculty at Portland State are disinvested and disempowered in the existing institutional structure governing the processes of career advancement and promotion. What in theory was a system meant to promote objective standards for evaluation and prospects for career 
advancement has, in effect, facilitated the division of faculty along the axis of tenure-track and non-tenure track, empowered the shrinking contingent of tenure-track faculty by elevating their position as the institutional representative for faculty through the Faculty Senate, and empowering a Board of Trustees to manage the affairs of the University with little meaningful oversight.

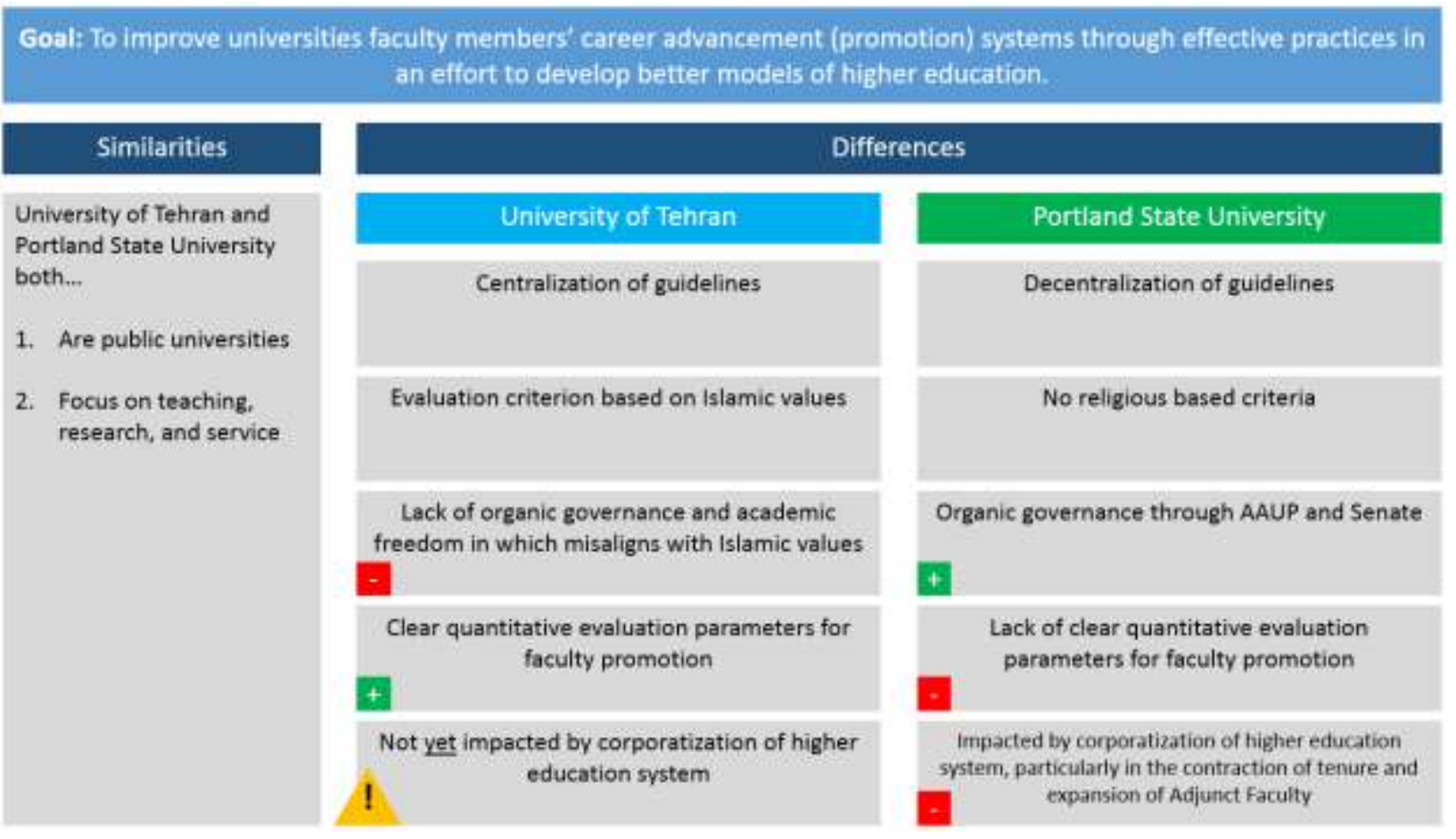

Figure 1. Summary of Key Findings

Description: While the University of Tehran and Portland State University are similar as public universities in which faculty career advancement is focused on teaching, research, and service, this figure reflects five key aspects in which the two institutions diverge. The plus symbols signify the authors' recommendations of effective practices (for example, organic faculty governance, and clear quantitative parameters for faculty evaluation). The triangular exclamation point symbol signifies an uncertain future outcome. In this case, that Iranian institutions of higher education have thus far largely avoided the deleterious consequences of higher education corporatization witnessed in the United States, but the future of this trend remains uncertain.

\section{Conclusion}

The aim of this article has been to highlight the similarities and differences in faculty career advancement (promotion) systems in the Iranian and American systems of higher education. As summarized in Figure 1, our research has shown that while both the University of Tehran and Portland State University are public institutions emphasizing teaching, research, and service as key criteria for faculty evaluation, they differ in five important respects. The University of Tehran implements a more centralized process for faculty career advancement in contrast to the devolution of decision-making authority to the college and departmental level at Portland State University. Secondly, the University of Tehran applies additional criteria pertaining to Islamic values which lack a clear equivalent in the American system of public higher education. From an objective management perspective, neither of these first two differences is inherently preferable to the other, and instead the cultural, social, and political context within which each system operates dictates their applicability.

The final three differences which emerge from our comparative analysis (governance, clarity of parameters, and corporatization) more clearly lend themselves to making specific recommendations as to how to improve faculty career advancement systems. First, the University of Tehran should adopt institutional mechanisms for organic governance as a way for faculty members to have a greater degree of control and input regarding their evaluation criteria. For example, the models of the AAUP and Faculty Senate in the case of Portland State University should be studied and implemented in this context. Faculty participation in university committees is essential for effective governance. Furthermore, this decentralization will promote greater academic freedom, which is not necessarily in 
contradiction with the Islamic values which are at the core of the University of Tehran system. (Note 3) On the other hand, Portland State University would benefit from looking closely at the effort to establish clear quantitative parameters for faculty promotion at the University of Tehran. Though the specific parameters may vary, the impetus to outline clear expectations and transparency in the evaluation process is, we contend, a step in the right direction. Finally, the University of Tehran should avoid the deleterious tendencies associated with the corporatization of higher education seen in the case of Portland State University, and indeed across the spectrum of American public institutions of higher education. The shrinking of tenure and the growth of Adjunct Faculty at Portland State University undermine the institution's primary goals in the domains of teaching, research, and community outreach/service. Learning from these shared experiences, both the University of Tehran and Portland State University specifically, and institutions of higher education in Iran, the United States, and elsewhere, should seek to learn from their similarities and differences, and in doing so strive toward the creation of more effective practices not only in terms of faculty career advancement systems, but also in moving toward developing more effective models of higher education.

It is necessary that research skills and their outcomes, such as scientific and technological innovation, assist and contribute to elevating teaching skills in order to improve the quality of learning on a national and international level for universities. For example, the result of this research article can be used to help create a context for comparing faculty members' career advancement system (promotion) guidelines across variable settings in an effort to proactively and continuously improve the state of higher education. Our analysis shows that the integrated collaboration of the three criteria of Research (R), Teaching (T), and Service (S) is essential in achieving this goal.

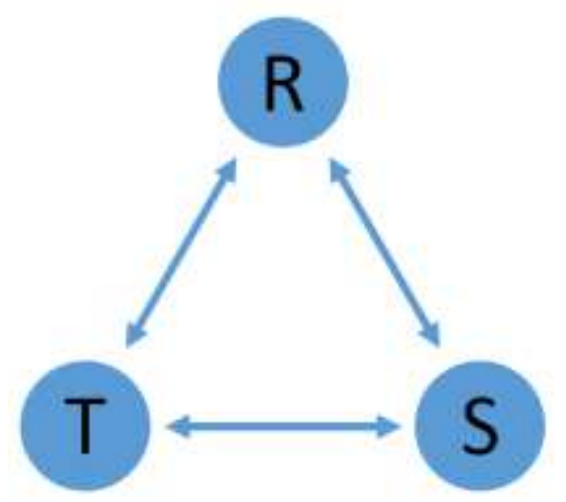

Figure 2. Integrated Model of Three Criteria for Career Advancement

Description: The bidirectional arrows between Research $(\mathrm{R})$, Teaching $(\mathrm{T})$, and Service $(\mathrm{S})$ indicate that these three categories should be understood more as integrated, overlapping, and mutually reinforcing. This conceptualization challenges the dominant view of these categories static and compartmentalized.

\section{References}

A Climate of Fear for Adjunct Faculty. (2017). AAUP correspondence. Retrieved from https://www.aaup.org/reports-publications/aaup-policies-reports

Altbach, P.G. (2015) Higher Education and the WTO: Globalization Run Amok. International Higher Education, 23, 2-4. https://doi.org/10.6017/ihe.2001.23.6593

Altbach, P.G., \& Knight, J. (2007). The Internationalization of Higher Education: Motivations and Realities. Journal of Studies in International Education, 11(3/4), 290-305. https://doi.org/10.1177/1028315307303542

Bradley, D., Yerichuk, D., Dolloff, L., Galway, K., Robinson, K., Stark, J., \& Gould, E. (2017). Examining Equity in Tenure Processes at Higher Education Music Programs: An Institutional Ethnography. College Music Symposium, 57. https://doi.org/10.18177/sym.2017.57.sr.11336

Bussmann, S., Johnson, S.R., Oliver, R., Forsythe, K., Grandjean, M., Lebsock, M., \& Luster, T. (2017). On the Recognition of Quality Online Course Design in Promotion and Tenure: A Survey of Higher Ed Institutions in the Western United States. Online Journal of Distance Learning Administration, 20(1). Retrieved from http://www.westga.edu/ distance/ojdla/spring201/bussmann_johnson\%20_oliver_forsythe_grandjean_lebsock_ luster201.html 
Bylaws of the Board of Trustees of Portland State University. (2016). Retrieved from https://www.pdx.edu/board/board-bylaws

Constitution of the Portland State University Faculty. (2016). Retrieved from https://www.pdx.edu/faculty-senate/sites/www.pdx.edu.faculty-senate/files/constitution.pdf

Flaherty, C. (2017). The More Things Change. Retrieved from https://www.insidehighered.com/news/2017/04/11/aaup-faculty-salaries-slightly-budgets-are-balanced-backs-ad juncts-and-out-state

Gross-Schaefer, A., Gala, S., Jaccard, J., \& Vetter, L. (2015). Being Honest About Tenure in the United States: The Need for Tenure System Reform within Institutions of Higher Education. International Journal of Social Science Studies, 3(4), 25-36. http://dx.doi.org/10.11114/ijsss.v3i4.827

Islamic Republic of Iran Ministry of Science, Research, and Technology. (2017). Retrieved from https://www.msrt.ir/en

Mills, N. (2012). The Corporatization of Higher Education. Dissent, 59(4), 6-9. https://doi.org/10.1353/dss.2012.0087

Oregon Administrative Rules of the Oregon State System of Higher Education. (1996). Section 580-21-100. Retrieved from http://library.state.or.us/repository/2015/201510081347304/index.pdf

Oregon State University's Faculty Handbook. (2016). Promotion and Tenure Guidelines. Retrieved from http://oregonstate.edu/admin/aa/faculty-handbook-promotion-and-tenure-guidelines

Ott, M., \& Cisneros, J. (2015). Understanding the Changing Faculty Workforce in Higher Education: A Comparison of Full-Time Non-Tenure Track and Tenure Line Experiences. Education Policy Analysis Archives, 23(90). http://dx.doi.org/10.14507/epaa.v23.1934

Portland State University. (2014). Policies and Procedures for the Evaluation of Faculty for Tenure, Promotion, and Merit Increased. Retrieved from https://www.pdx.edu/faculty-senate/sites/www.pdx.edu.faculty-senate/files/PT\%20Guidelines\%20\%204-23-201 4.pdf

Portland State University. (2017). About Portland State University. Retrieved from https://www.pdx.edu/about-portland-state-university

University of Tehran. (2017). Organization. Retrieved from http://ut.ac.ir/en/page/770/organization

Youn, T.I.K., \& Price, T.M. (2009). Learning from the Experience of Others: The Evolution of Faculty Tenure and Promotion Rules in Comprehensive Institutions. The Journal of Higher Education, 80(2), 204-237. http://dx.doi.org/10.1080/00221546.2009.11772139

\section{Notes}

Note 1. Our usage of 'contexts' here is meant to generally imply different geographic, historical, cultural, and sociopolitical contexts, and this contextual difference is clearly reflected in the case selection of the University of Tehran and Portland State University.

Note 2. 'Houza,' or traditional religious schools

Note 3. For example, as noted in the Qur'an, Surah Al-Imran (3:159), 'It was by the mercy of Allah that thou wast lenient with them (O Muhammad (PBUH)), for if thou hadst been stern and fierce of heart they would have dispersed from round about thee. So pardon them and ask forgiveness for them and consult with them upon the conduct of affairs. And when thou art resolved, then put thy trust in Allah. Lo! Allah loveth those who put their trust (in Him).' Pickthall trans., emphasis added 